\title{
Inscripción inédita de Garciez (Jaén)
}

\author{
Ildefonso Ramirez González y Jerónimo Sánchez Velasco
}

\section{RESUMEN}

Damos a conocer un ara funeraria inédita aparecida en Garciez (Jaén) 1 . El tipo de soporte es exclusivo de la zona, lo que quizá indica la existencia de un taller lapidario. La singular onomástica reflejada en la inscripción nos lleva a pensar en posibles emigrados.

\section{SUMMARY}

We release an unpublished funeral altar stone, appeared in Garciez (Jaén). The type of base is exclusive of the region. This fact could reflect the existence of a lapidary workshop. The curious personal names on the inscription make us think of possible immigrants.

La siguiente inscripción se conserva en el domicilio de los Sres. Quesada, en la c./ Alejandro Peris 10, Garciez de Bedmar (Jaén). Fue hallada por uno de sus hijos, Luis Quesada Fuentes, durante unas labores agricolas en sus tierras. A ellos nuestro más sincero agradecimiento por todas las facilidades que nos proporcionaron para realizar la autopsia de la pieza.

El lugar del hallazgo puede considerarse como agrvm ossigitanvm, pues toda la zona comprendida entre el río Bedmar y el Torres es una comarca natural dominada por el oppidvm iberorromano de Cerro Alcalá, la antigua Ossigi Latonivm, por lo que seguramente perteneció al Conventvs Cordvbensis.

1 Queremos agradecer públicamente la inestimable ayuda que nos han prestado los profesores A. U. Stylow, A. Ventura y A. ARÉVAlo, generosos maestros en este menester de la Epigrafía. 
Se trata de un ara rectangular, muy alargada, de piedra caliza de color beige claro, probablemente local. Las medidas del soporte son: $151 \times 27 \times$ $18 \mathrm{~cm}$. El campo epigráfico mide $74 \times 27 \mathrm{~cm}$. La pieza consta de peana, zócalo, fuste, cornisa y coronamiento, conservándose en su totalidad en un excelente estado.

La peana, de $43 \mathrm{~cm}$ de altura, está groseramente acabada, entre otras razones porque no iba a ser vista, pues su función era la de fijar el ara al suelo. Ésta se une a las molduras del zócalo por una media caña cóncava.

La decoración del zócalo y la cornisa es formalmente idéntica: una faja cóncava de 9 y $12 \mathrm{~cm}$ respectivamente. En ambos casos, la moldura sólo sobresale $2 \mathrm{~cm}$ de la superficie del campo epigráfico. La única diferencia es que entre la peana y el zócalo hay una media caña cóncava y entre la cornisa y el coronamiento un bisel inverso (lámina 1).

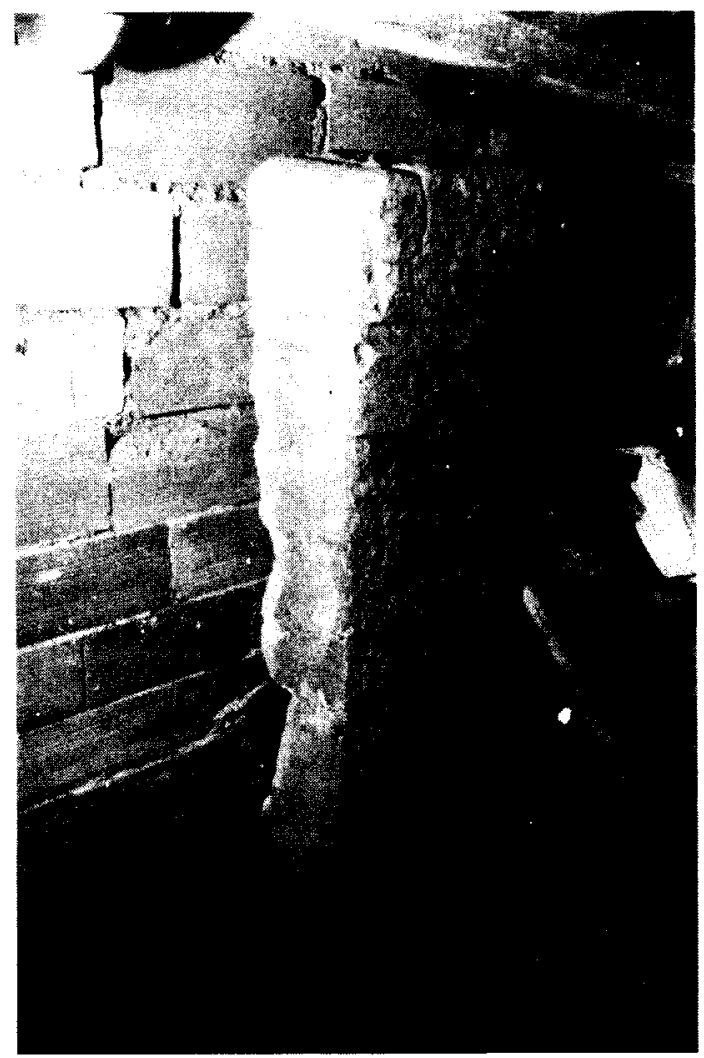

Lámina 1. Fotografía general del ara centrada especialmente en las características del soporte. 
El coronamiento (lámina 2) presenta un focvs circular bastante grande en relación a la anchura de la pieza, pues mide $12 \mathrm{~cm}$ de diámetro. Éste es casi plano, con una profundidad de tan sólo $2 \mathrm{~cm}$. No hay frontón, por lo que el coronamiento resulta bastante sobrio y monolítico. A ambos lados hay sendos pulvinos, sólo insinuados por unas profundas incisiones que los individualizan del focvs como dos cilindros sin decoración frontal ni lateral. El campo epigráfico no está delimitado ni por molduras ni por incisiones. Posee ocho líneas sin una ordenación demasiado acertada.

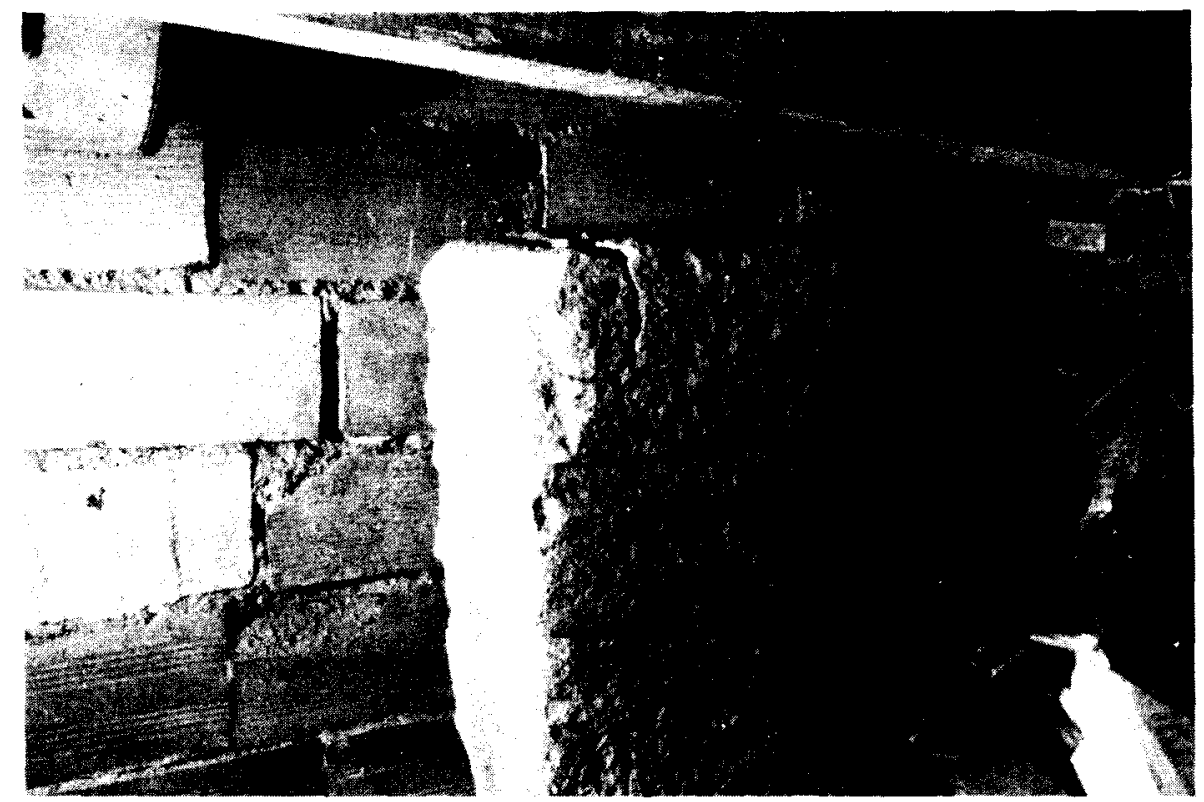

Lámina 2. Particular del coronamiento del ara.

Las letras son capitales librarias de trazo poco profundo pero muy bien ejecutado. Sus dimensiones son 4'5 (1.1), 4 '5 (1.2), 5 (1.3), 4'5-5 (1.4), 5 (1.5), 5 (1.6), 4'5 (1.7) y $4 ' 5 \mathrm{~cm}$ (1.8).

Los interlineados miden $2^{\prime} 5 \mathrm{~cm}$ en todos los casos. Las interpunciones son incisiones profundas en diagonal.

Se puede leer (lámina 3):

$$
\begin{gathered}
\text { D M S } \\
++C+\text { ORIA } \\
\text { GALLICA } \cdot \text { AN }
\end{gathered}
$$




\section{P PIAINSV \\ $5 \quad$ IS $P \cdot P \cdot$ CORN \\ MAVRVS . \\ POSVIT \\ $H \cdot S \cdot E \cdot S \cdot T \cdot T \cdot L$}

$D$ (iis) M(anibvs) S(acrvm) / Lictoria $\cdot /{ }^{3}$ Gallica $\cdot$ an(norvm) $/ L X \cdot$ pia in sv / is · P(vblivs) - Corn(elivs) / ${ }^{6}$ Mavrvs $\cdot /$ posvit / $H$ (ic) s(ita) e(st) s(it) t(ibi) t(erra) I(evis)

"Consagrado a los Dioses Manes. Lictoria Galica de sesenta años, piadosa con los suyos, aquí está. Que la tierra te sea leve. Publio Cornelio Mauro puso (el ara)".

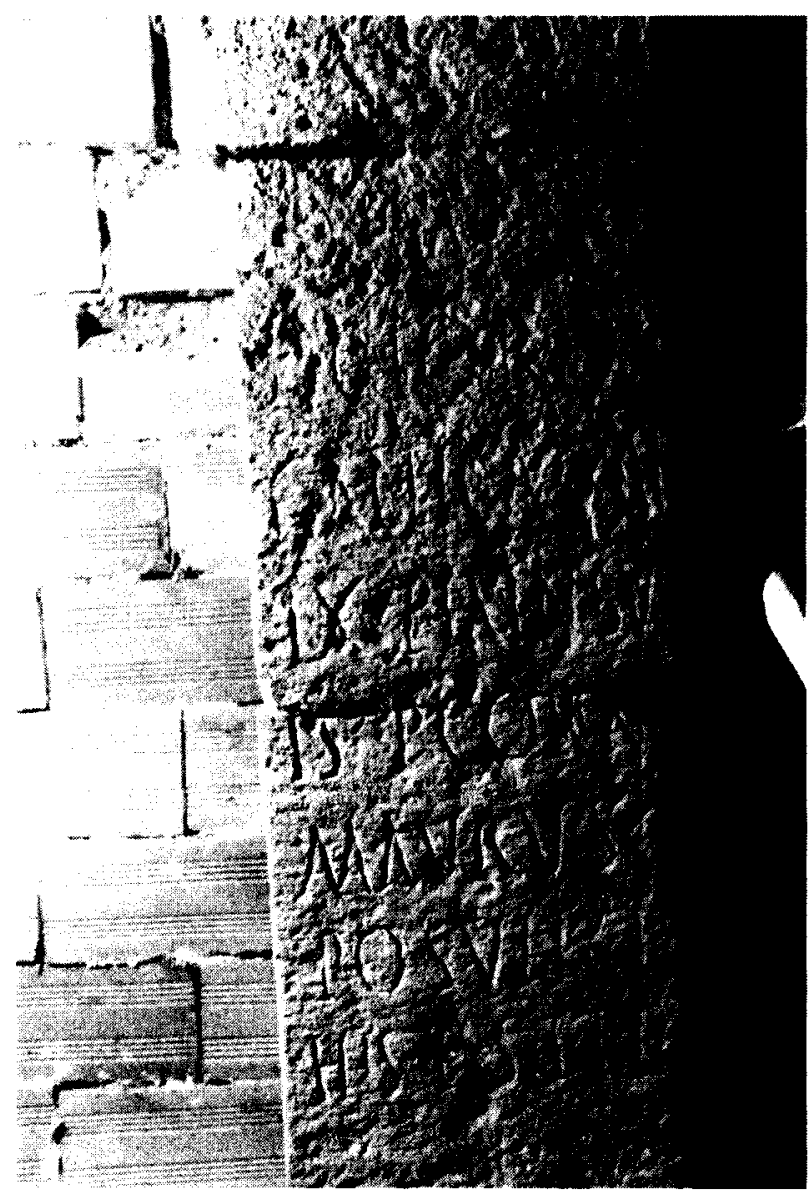

Lámina 3. Texto epigráfico. 
En I.1, por el fuerte deterioro de la superficie, sólo se aprecian los trazos de las letras, no pudiendo especificar si entre ellas existe alguna interpunción. Hay tres letras en 1.2 que no se pueden leer bien, pues sólo se conserva la mitad inferior de los trazos, donde los refuerzos no son demasiado significativos. Con las letras que nos han llegado en mejor estado podemos restituir con seguridad en 1.2 un nomen acabado de +icioria/+ictoria. Como no se han documentado gentilicios en + icioria ${ }^{2}$, cabe suponer que nos enfrentamos a la segunda posibilidad. Contamos fundamentalmente con tres nomina que tienen tal terminación: Fictoria, Pictoria o Lictoria. El primer caso es poco probable, pues esta letra no posee refuerzo inferior, sino que imita a la $I$. Un nomen iniciado en $P$ tampoco entra en lo posible, pues, aunque tiene el refuerzo inferior, debería haberse conservado algún trazo de la panza cercano a la siguiente letra. Por estas razones nos decantamos por la última opción, Lictoria. En I.3 la fuerte erosión de la pieza dificulta la lectura, especialmente allí donde los refuerzos de las letras han sido muy afectados, caso de las L. La misma causa impide leer con claridad el nexo $A N$ al final de la línea.

Sólo queda comentar que en ningún caso las $A$ cuentan con el travesaño horizontal, los refuerzos nunca sobresalen excesivamente de la caja y la última línea parece tener un dvctvs un poco más descuidado. Cada palabra va separada por una interpunción, salvo en I.4, donde la expresión pia in suis va unida como si de una sola palabra se tratara. También es destacable la abreviación del nomen y el espacio vacío al final de l.7, tras posuit, asi como la ruptura en 1.8 de la sangría seguida a lo largo de todo el texto para que cupiera la fórmula final.

Por el tipo de escritura, por las fórmulas y por la abreviación del nomen podemos fechar la inscripción en la segunda mitad del s. $\|^{3}$.

A lo largo del texto no se indica ninguna relación familiar o de dependencia entre la difunta y quien dedicó el ara, por lo que hay que suponer que se trata del marido que la encarga para su mujer. De no ser así, se hubiera especificado si se trataba de un hijo, de un esclavo o de un liberto.

\footnotetext{
2 Hemos consultado fundamentalmente SOLIN, H. y SALOMIES, O.: Repertorium nominum gentilium et cognominum latinorum. 1994.

3 Para las dataciones del soporte y de la paleografia cf. StYLow, A.U.: "Los inicios de la epigrafía latina en la Bética. El ejemplo de la epigrafía funeraria", en BELTRÁn LloRIS. F. (ed.): Roma y el nacimiento de la cultura epigráfica en Occidente. Zaragoza, 1995, pp. $219-238$. Específicamente para la datación del soporte, cf. Beltrán Fortes, J.: Las arae de la Baetica. (Tesis doctoral inédita). Málaga, 1988.
} 
Más interesante es la onomástica de la pareja. Respecto a la mujer, el nomen Lictoria es excepcional, siendo esta la primera vez que aparece en Hispania ${ }^{4}$. Lo mismo ocurre con el cognomen, Gallica, constatado una sola vez en todas las inscripciones peninsulares ${ }^{5}$. La rareza de los nombres de la difunta junto con su claro sentido étnico ${ }^{6}$ nos hacen pensar en una emigrada desde alguna de las provincias donde estos nombres eran más frecuentes. El caso del marido es menos extraño, pues cuenta con un praenomen y un nomen frecuentísimos en la zona y en toda Hispania ?. Aunque menos usual, el cognomen Mavrvs está bien representado en Hispania, y en la Bética en especial ${ }^{8}$. También el marido posee un cognomen étnico, lo que da pie a pensar en la posibilidad de otro emigrado.

De cualquier forma, lo realmente difícil es establecer si son emigrados voluntarios o forzosos, pues sus nombres no indican extracción servil ${ }^{9}$ y en la inscripción no se especifica si son libertos.

El tipo de ara es exclusivo de la zona del valle del Alto Guadalquivir, pues los dos ejemplares que más similitudes tienen con el ara de Garciez se han hallado en Jimena (Jaén) y en la aldea de Almansa (Chilluévar, Jaén) ${ }^{10}$. Los paralelos son notables: a) en ambas tenemos unas proporciones similares, más propias de las estelas que de las aras; b) no existen molduras complejas, sino grandes fajas (planas o cóncavas) insinuadas por profundas incisiones; c) los coronamientos son masivos y monolíticos, uniendo los pulvinos con el focvs, y sin que exista frontón; d) en los tres casos (contando la inscripción que aquí tratamos) las letras son capitales librarias muy similares y miden por norma $4^{\prime} 5 \mathrm{~cm}$, siendo el máximo $5 \mathrm{~cm}$ y el mínimo $3^{\prime} 5$.

Tales similitudes nos llevan a plantear la hipótesis de un taller lapidario en la zona, cuya confirmación definitiva debería venir del análisis petrológico de las calizas de las distintas aras.

\footnotetext{
4 Existe un paralelo en $C / L$ XI, 3895. Se trata de una mujer llamada Lictoria Chaerusa.

5 ABASCAL, J.M.: Los nombres personales en las inscripciones latinas de Hispania. Lleida, 1994, pág. 337; una excelente fotografía de la pieza en ALFöLDY G.: Die Römische Inschriften von Tarraco, Berlin, 1975, vol. II, fig. 72/2.

6 KaJANTO, 1.: The Latin Cognomina, pág. 195. Según el autor, este tipo de cognomina indican el origen de la persona y no suelen pasar de padres a hijos, a no ser que sean frecuentísimos (Sabino, Romano, etc.). En especial, se ha constatado en las provincias de Gallia Ciscalpina, Venetia, Liguria y Corsica.

7 ABASCAL, 1994, pág. 116, afirma que es el tercer gentilicio más frecuente en Hispania, con un $4{ }^{\prime} 65 \%$ de representación.

8 ABASCAL, 1994, pág. 421; de 17 registrados, 10 están en la Bética.

9 Kajanto, 1965, págs.. 50 y 206. En el caso de Mavrvs, el autor nos da una relación esclavo/libre de 3 de 42 hombres y 2 de 39 mujeres, lo que nos da una proporción infima.

10 GONZÁlez Román, C.: "Inscripciones romanas inéditas de la provincia de Jaén. II". Cuad. Preh. Gr 14-15, 1989-90, págs. 299-314, n 3 y 5 .
} 